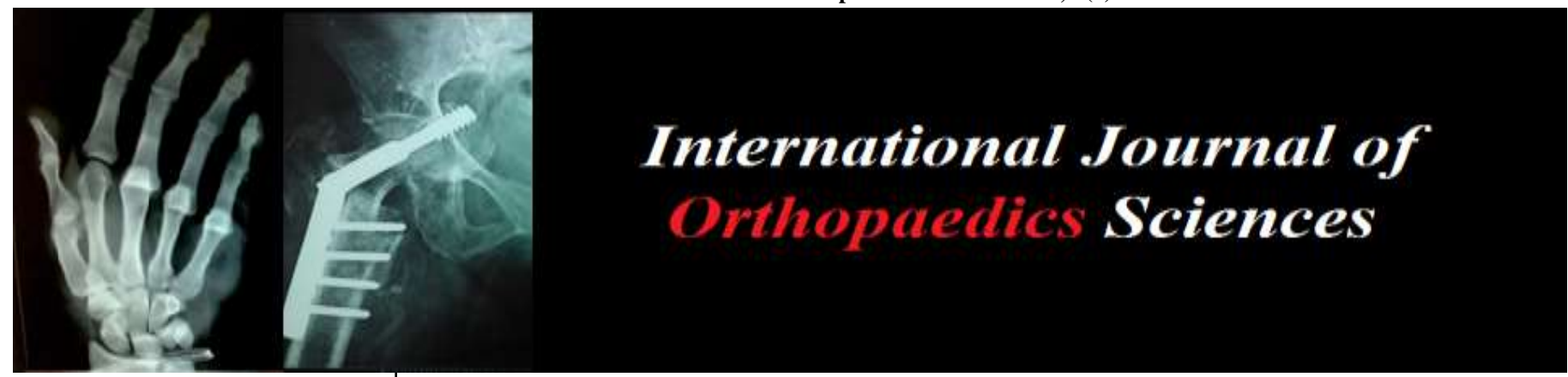

E-ISSN: 2395-1958

P-ISSN: 2706-6630

IJOS 2021; 7(2): 364-368

(C) 2021 IJOS

www.orthopaper.com

Received: 20-02-2021

Accepted: 22-03-2021

\section{JV Modi}

(Head of Department)

Dept. Of Orthopaedics, B.J.

Medical College and Civil

Hospital, Ahmedabad, Gujarat, India

\section{Pratik Vala}

(2ND Yr Resident) Dept. Of Orthopaedics, B.J. Medical College and Civil Hospital,

Ahmedabad, Gujarat, India

\section{Nishil Pate}

(1 1 st Yr Resident) Dept. Of

Orthopaedics, B.J. Medica

College and Civil Hospital,

Ahmedabad, Gujarat, India
Corresponding Author: JV Modi

(Head of Department) Dept. Of Orthopaedics, B.J. Medical College and Civil Hospital, Ahmedabad, Gujarat, India

\section{Atlanto-axial fixation in traumatic Atlanto-axial dislocation with odontoid process fracture}

\section{JV Modi, Pratik Vala and Nishil Patel}

DOI: https://doi.org/10.22271/ortho.2021.v7.i2e.2653

\section{Abstract}

Atlanto-axial segment is made up of Atlas (c1) and axis (c2) vertebrae. This segment is responsible for rotational movement in the region of the cervical spine. Instability and damage to this segment can occur due to various reasons and can lead to abnormal motion with neurological consequences. Here we describe a case of 21 year old male with traumatic Atlanto-axial dislocation with odontoid process fracture with left upper limb weakness with gait instability treated with posterior vertebral fixation using pedicle screws with its clinical as well as radiological outcome.

Keywords: Atlanto-axial dislocation, rotational instability, posterior fixation, cord compression

\section{Introduction}

The Atlanto-axial articulation is a complex of three synovial joints, which join the atlas (C1) to the axis $(\mathrm{C} 2)$.

- Lateral Atlanto-axial joints (2)

- Median Atlanto-axial joint

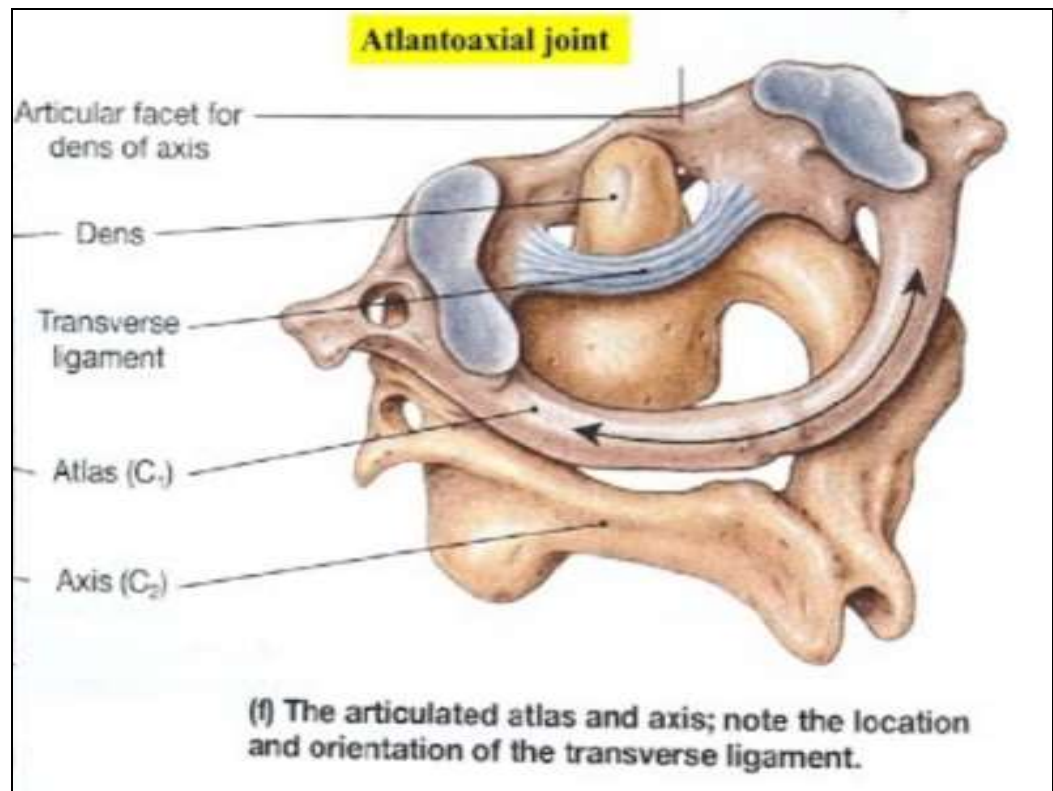

\section{Bones}

In all the vertebrae, cervical vertebras are smaller in size than all the other vertebrae's to allow movements of head and to protect cranial nerves.

Occiput - base of skull which articulates with atlas

Atlas $(\mathrm{C} 1)-1^{\text {st }}$ cervical vertebrae which is ring shaped having thick anterior and thin posterior arch without body. 
Axis $(\mathrm{C} 2)-2^{\text {nd }}$ cervical vertebrae having large vertebral body with odontoid process (dens) over which atlas rotates.

\section{Ligaments}

Nuchal ligament: it is a continuation of supraspinous ligament which attaches to the tip of spinous processes from $\mathrm{C} 1-\mathrm{C} 7$ and also provides attachment to the rhomboid and trapezius.

Occipito-atlantal ligament complex: 4 ligaments (anterior, posterior and 2 lateral) which connects occiput to atlas Occipito-axial ligament complex: 4 ligaments (occipiotaxial, 2 alar and apical) connects occiput to axis

Atlanto-axial ligament complex: 4 ligaments (posterior, anterior and 2 lateral) connecting atlas to axis

Cruciate ligament complex: stabilises the Atlanto-axial joint

Transverse ligament: which connects lateral masses of atlas and anchors dens in place. Also acts as a posterior articulation of the atlanto-axial joint.

Anterior and Posterior longitudinal ligaments: these long ligaments run full length of the vertebral column which covers vertebral bodies and intervertebral discs.

Ligamentum Flavum: connects laminate of adjacent vertebrae.

Interspinous vertebrae: connects spinous processes of adjacent vertebrae.

\section{Function}

Atlanto-axial joint allows,

- 10-15 degrees of flexion/extention

- 30 degrees of axial rotation

- Minimal lateral flexion

\section{Parameters}

A. Predental space: it is a space between anterior arch of atlas and dens of axis. Beyond $3 \mathrm{~mm}$ is suggestive of dens fracture or disruption of transverse ligament.

B. Chamberlain line: it is a line measured from dorsal lip of foramen magnum to the posterior portion of hard palate. Superior tip of odontoid doesn't exceed beyond this line. Beyond $5 \mathrm{~mm}$ extension above this line is abnormal.

C. McGregor line: it is a modification of the chamberlain line and measured from posterior portion of hard palate to the lowest edge of mod line occipital surface.

D. McRae line: it is measured from anterior margin of foramen magnum to the posterior border and odontoid tip should not cross this line.

E. Anderson and D'alonzo classification for dens fracture

Type-I: Upper dens

Type-II: Base of dens

Type-III: Body of axis

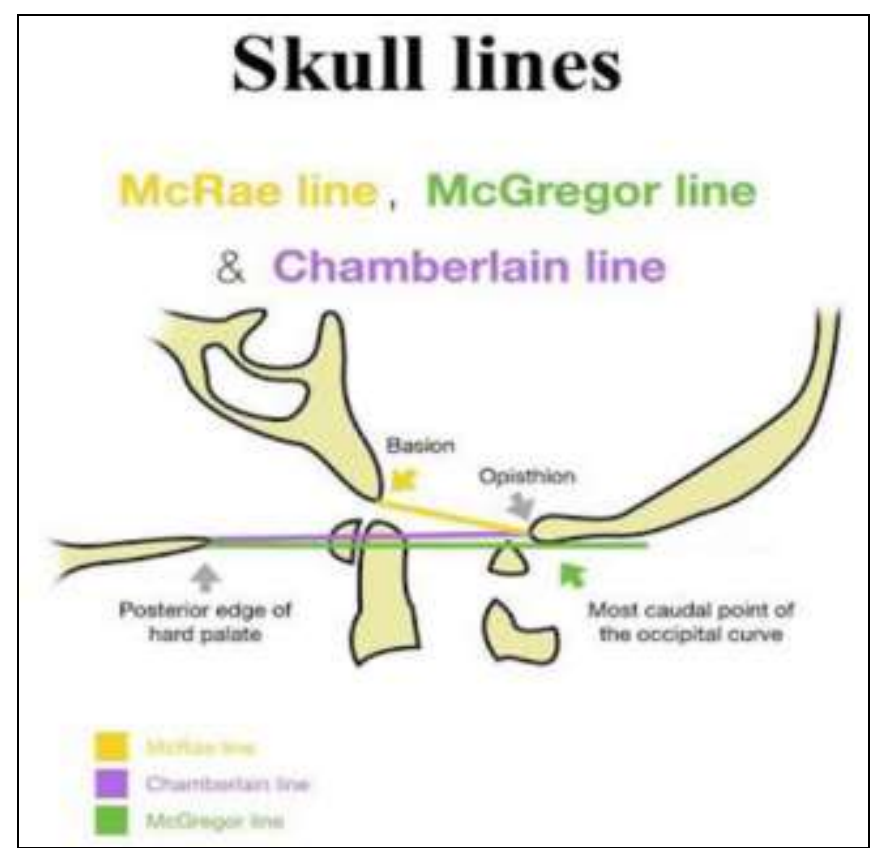

\section{Case description}

21 year old male with complaint of neck pain with left upper limb weakness since 1 week which is due to road traffic accident. Post trauma Patient was unable to stand or walk with normal bowel and bladder function. Patient was taken to Government hospital in Uttar Pradesh where all the radiological investigations were done. MRI and CT scan of this patient have predental space of $7 \mathrm{~mm}$ which is suggestive of atlanto-axial dislocation and fracture of odontoid process

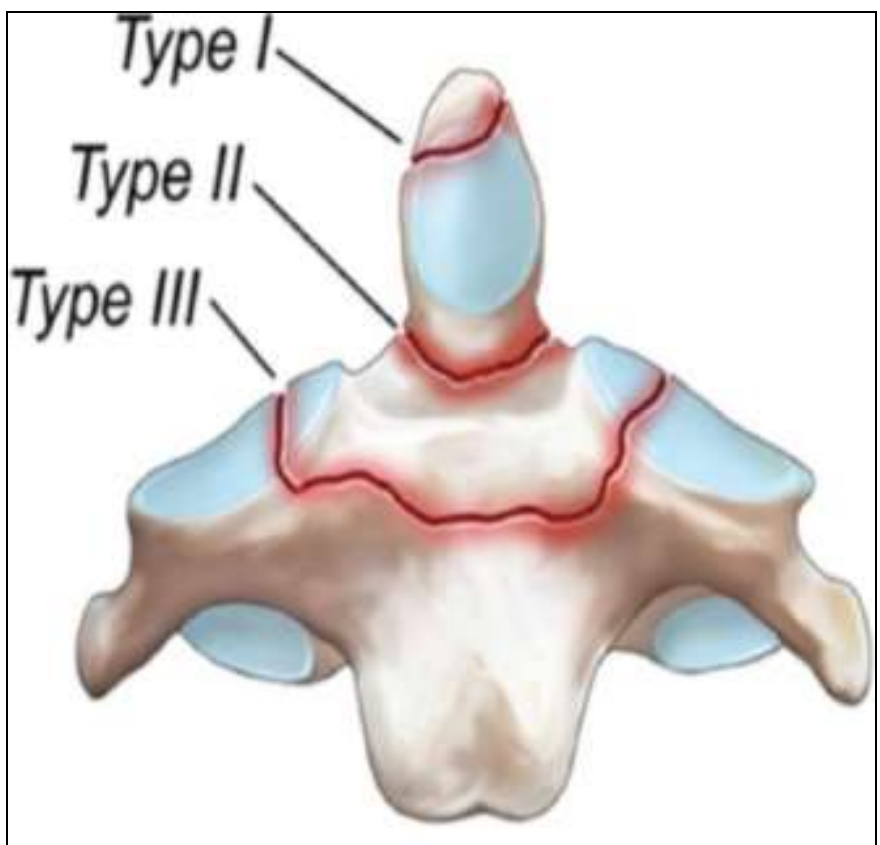

which caused compression over brainstem due to which patient developed weakness in left upper limb. When patient came to $\mathrm{CHA}$ tong insertion done and traction given then traction CT scan done for checking stability of Atlanto axial joint and patient was operated $\mathrm{C} 1-\mathrm{C} 2$ fixation with rod and screw fixation with posterior approach and after 2 days of surgery patient's neurology got improved and post operative ct scan done. 


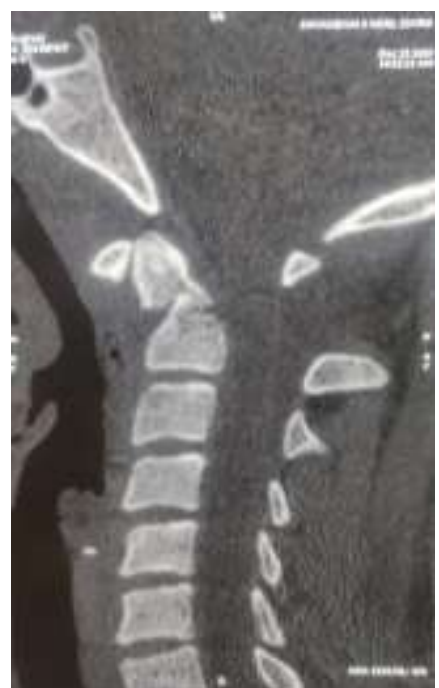

Pre-op CT.

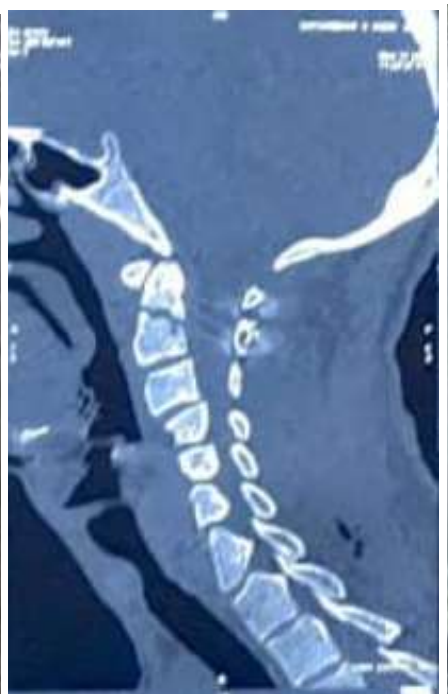

Post-op CT

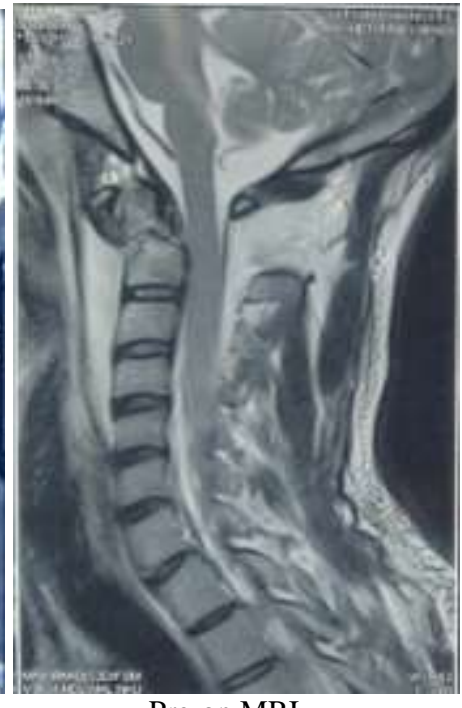

Pre-op MRI

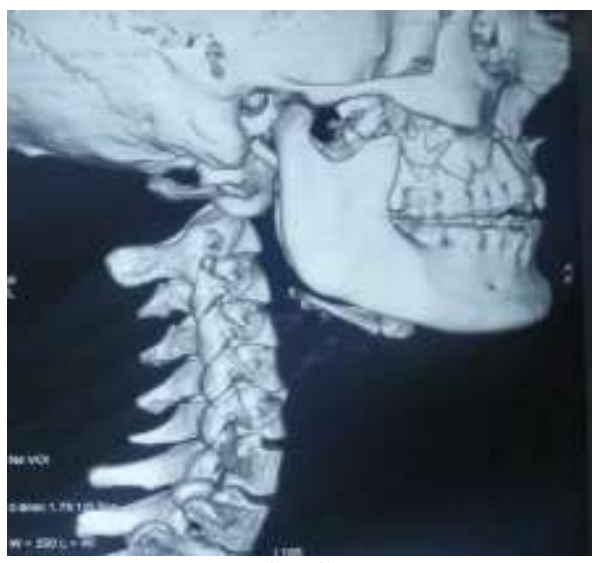

Pre-op 3D CT

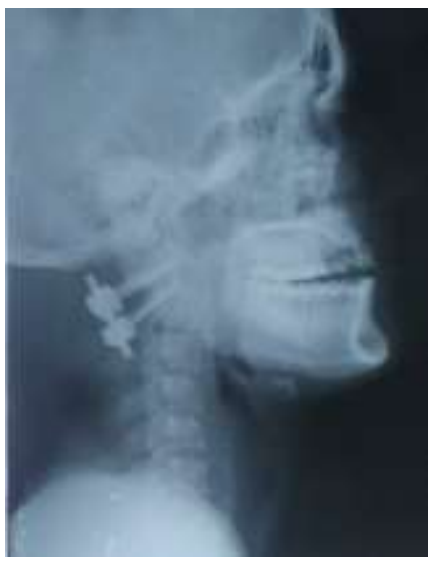

Post-op xray

\section{Discussion}

Traumatic C1/ C2 dislocation appears to be rare but possibly life-threatening entities of injury coming along with a high risk of vascular and neurological disorders due to vitally important structures present in this region ${ }^{[1-4]}$. Role of structures which contribute to dislocation is not completely understood.

Trauma doesn't necessitate neurovascular complications due to relatively wide bony spinal canal at $\mathrm{C} 1-\mathrm{C} 2$ level. Distraction injuries, however, may lead to distortion as well as to rupture of the spinal cord depending on the force applied. Accompanying vascular injuries affect the vertebral artery commonly, but may involve the carotid arteries as well [3]. Especially patients, who present a 'high-riding' variant of the vertebral artery, are at risk of vessel dissection or rupture, due to decreased limitation provided by bony structures.

As these types of injuries come along with a high grade of instability causing consequential disorders possibly, understanding of the injuries' morphology is of essential importance, in order to set the correct diagnosis and to apply the appropriate treatment.

Based on recommendations and cases presented in the literature as well as on our present results we conclude that in cases of high-energy trauma as well as in cases of low-energy trauma in older patients it appears to be highly necessary to perform CT imaging after trauma. If atlantoaxial dislocation is diagnosed, angiography is essential. Although direction of atlantoaxial dislocation may lead to the knowledge about all injured structures, MRI has to be performed, in order to visualize injures structures clearly. Moreover, MRI presentation may give evidence about spinal cord injury ${ }^{[3,10]}$. Regarding treatment of atlantoaxial dislocation, there is consensus that reduction has to be performed as soon as possible in all cases, in order to prevent residual instability and development of permanent deformity. To date it is known that time to reduction correlates with the recurrence of dislocation recurrence and failure of reduction ${ }^{[4]}$. Afterwards, immobilization and rigid fixation are necessary due to the high, residual instability. Wise et al. described one case of solitary rotatory atlantoaxial dislocation caused by ligamentous injury, which they treated successfully using brace immobilization. Fielding proposed conservative treatment using brace immobilization for rotatory dislocations of $\mathrm{C} 1$ and $\mathrm{C} 2$ as well. A close-mesh follow-up, including functional imaging is necessary, in order to prove the treatment's success and to prevent ongoing atlantoaxial instability in the long-term ${ }^{[4,11]}$.

Most authors, however, prefer surgical stabilization in adult lesions due to the residual instability after reposition of the facet joints, as do we ${ }^{[8,12]}$. As rupture or dislocated bony avulsion of the transverse atlantal ligament appears to be clear indicators for the need of surgical stabilization, horizontal atlantoaxial dislocations as well as dissociations have to be treated surgically performing atlantoaxial instrumentation according to the recommendations of Dickman and Kandziora $[13,14]$. Moreover it is known that there is a need of surgical intervention, if a fracture of the odontoid process and a rupture of the transverse atlantal ligament are combined ${ }^{[15]}$. As shown in the present cohort, surgical management appears to come along with good outcome. 
Some authors favored performing closed reduction and fixation using a halo fixator. This method, however, failed in three cases. Lenehan et al. published a case in which closed reduction using a halo fixator failed in a patient suffering from $\mathrm{C} 1 / \mathrm{C} 2$ lateral dislocation with fracture of the odontoid process ${ }^{[12]}$. Przybylski et al. reported about a 35-year-old man suffering from vertical atlantoaxial dislocation with additional type III odontoid fracture. The authors pointed out that atlantoaxial dissociation increased in the further course despite stabilization with halo fixator. Therefore they concluded that this method does not eliminate the vertical instability as it boosts it to the contrary. This method, however, is advantageous, if the treatment is delayed or the dislocation is not correctly reduced in the first step.

Several methods are known in order to run surgical fixation of $\mathrm{C} 1$ and C2. Transarticular fixation using Magerl's method and C1 mass with $\mathrm{C} 2$ transpedicular screw fixation according to Goel and Harms are commonly used resulting in satisfying long-term results ${ }^{[1,16]}$. Other screw constructs for atlantoaxial fixation include Wright's C1 lateral mass and C2 translaminar screw construct or the $\mathrm{C} 1$ lateral mass and $\mathrm{C} 2$ pars screw construct ${ }^{[17]}$. Du et al. performed a meta-analysis of biomechanical testing of these atlantoaxial fixation techniques, which show good to excellent fusion rates in the literature. The authors concluded that all of these fixation techniques provide significant stabilization of axial rotation, flexion, and extension. Instrumentation constructs between lateral masses of $\mathrm{C} 1$ and translaminar screw placement at level $\mathrm{C} 2$, however, did not provide significant stabilization of lateral bending ${ }^{[18]}$.

From our point of view Goel's and Harms's technique is advantageous in comparison to the transarticular fixation in atlantoaxial dislocation. Firstly, the risk of relapsing dislocation may increase intraoperatively if a screw is inserted as the atlas is possibly pushed away. Secondly, especially in young patients, further violation of the facet joints has to be avoided in order to remove implants after consolidation. Findings of Lee et al. support our experience that C1 mass and $\mathrm{C} 2$ transpedicular screw fixation is beneficial compared to transarticular fixation regarding the consolidation rate ${ }^{[19]}$. In patients presenting with high-riding vertebral artery, however, other fixation techniques are advantageous ${ }^{[18]}$.

If there is a dissection of the vertebral artery, the patient has to get therapeutic anticoagulation by warfarin or phenprocoumon.

\section{Conclusion}

Here by, this is concluded that $\mathrm{C} 1-\mathrm{C} 2$ fixation is a treatment option in patient with traumatic Atlanto-axial dislocation with odontoid process fracture. Patient shows significant improvement clinically as well as radiologically without any significant increasing chances of immediate and early post operative complications.

\section{References}

1. Harms J, Melcher RP. Posterior C1-C2 fusion with polyaxial screw and rod fixation, The Spine Journal. 2001;26(22):2467-2471. View at: Publisher Site | Google Scholar

2. Adams VI. "Neck Injuries: II. Atlantoaxial dislocationa pathologic study of 14 traffic fatalities," Journal of Forensic Sciences 1992;37(2):565-573. View at: Publisher Site | Google Scholar

3. Chen Z, Jian FZ, Wang K. "Diagnosis and treatment of vertebral artery dissection caused by atlantoaxial dislocation," CNS Neuroscience \& Therapeutics, 2012;18(10):876-877, View at: Publisher Site | Google Scholar

4. Karampinas PK, Korres DS. "Atlantoaxial dislocation," The Axis Vertebra 2013, 79-85. View at: Publisher Site | Google Scholar

5. Cattrysse E, Barbero M, Kool P, Gagey O, Clarys JP, Van Roy P. "3D morphometry of the transverse and alar ligaments in the occipito-atlanto-axial complex: an in vitro analysis," Clinical Anatomy 2007;20(8):892-898. View at: Publisher Site | Google Scholar

6. Tubbs RS, Hallock JD, Radcliff V. et al., "Ligaments of the craniocervical junction: a review," Journal of Neurosurgery: Spine 2011;14(6):697-709. View at: Publisher Site | Google Scholar

7. Dreizin D, Letzing M, Sliker CW. et al., "Multidetector CT of blunt cervical spine trauma in adults," Radio Graphics 2014;34(7):1842-1865. View at: Publisher Site | Google Scholar

8. Johnson DP, Fergusson CM. "Early diagnosis of atlantoaxial rotatory fixation," The Journal of Bone \& Joint Surgery (British Volume) 1986;68(5):698-701. View at: Google Scholar

9. Li-Jun L, Ying-Chao H, Ming-Jie Y, Jie P, Jun T, DongSheng Z. "Biomechanical analysis of the longitudinal ligament of upper cervical spine in maintaining atlantoaxial stability," Spinal Cord 2014;52(5):342-347. View at: Publisher Site | Google Scholar

10. Sliker CW. "Blunt cerebrovascular injuries: imaging with multidetector CT angiography," Radiographics 2008;28(6):1689-1708. View at: Publisher Site | Google Scholar

11. Meyer C, Bredow J, Heising E, Eysel P, Müller L, Stein G. "Rheumatoid arthritis affecting the upper cervical spine: biomechanical assessment of the stabilizing ligaments," BioMed Research International, 2017, Article ID 6131703, 2017, 7. View at: Publisher Site | Google Scholar

12. Lenehan B, Guerin S, Street J, Poynton A. "Lateral C1C2 dislocation complicating a type II odontoid fracture," Journal of Clinical Neuroscience 2010;17(7):947-949. View at: Publisher Site | Google Scholar

13. Dickman CA, Mamourian A, Sonntag VKH, Drayer BP. "Magnetic resonance imaging of the transverse atlantal ligament for the evaluation of atlantoaxial instability," Journal of Neurosurgery 1991;75(2):221-227. View at: Publisher Site | Google Scholar

14. Kandziora F, Scholz M, Pingel A et al., "Treatment of atlas fractures: recommendations of the spine section of the german society for orthopaedics and trauma (DGOU)," Global Spine Journal 2018;8(2):5-11. View at: Publisher Site | Google Scholar

15. Greene KA, Dickman CA, Marciano FF, Drabier J, Drayer BP, Sonntag VKH. "Transverse atlantal ligament disruption associated with odontoid fractures," The Spine Journal 1994;19(20):2307-2314. View at: Publisher Site | Google Scholar

16. Magerl F, Seemann PS. "Stable posterior fusion of the atlas and axis by transarticular screw fixation," in Cervical Spine I, Springer, Vienna, Austria 1987, 322327. View at: Google Scholar

17. Wright NM. "Posterior C2 fixation using bilateral, crossing C2 laminar screws: case series and technical note," Journal of Spinal Disorders \& Techniques 2004;17(2):158-162. View at: Publisher Site | Google 
Scholar

18. Du JY, Aichmair A, Kueper J, Wright T, Lebl DR. "Biomechanical analysis of screw constructs for atlantoaxial fixation in cadavers: a systematic review and meta-analysis. Journal of Neurosurgery: Spine 2015;22(2):151-161. View at: Publisher Site | Google Scholar

19. Lee SH, Kim ES, Sung JK, Park YM, Eoh W. "Clinical and radiological Comparison of treatment of atlantoaxial instability by posterior $\mathrm{C} 1-\mathrm{C} 2$ transarticular screw fixation or C1 lateral mass-C2 pedicle screw fixation, Journal of Clinical Neuroscience 2010;17(7):886-892. View at: Publisher Site | Google Scholar 